\title{
Conversion, Simplification and Differentiation: Three Rural Housing Strategies in China Based on Self-built Housing and Construction Solidarity
}

\author{
By Dou Ruiqi*
}

\begin{abstract}
Based on the development of Construction Solidarity in the Chinese mainland led by Hsieh Ying-chun, this paper focuses on the comparison between self-built rural housing and cooperative housing through case studies on three villages where the design team carried out this practice, in order to investigate the housing philosophy of the conversion of the prototype, the simplification of technology and the differentiation of occupation when an architect takes part in rural residential construction.
\end{abstract}

\section{Introduction}

Housing is a complex issue of architecture which concerns people's livelihood and involves a lot of other research fields. However, since most dwellings in the countryside are currently built by local inhabitants, it is difficult for the architects to participate in design and research on rural housing, which has resulted in a series of problems. For instance, most of rural residences are built by directly applying standard design drawings, regardless of local practical activities, daily customs and traditional religious culture. Besides, semi-professional construction methods widen the gap of design and the construction level between urban and rural areas. Obviously these problems can hardly be solved by current housing modes such as unified construction by government, business operation by developers or self-building by villagers, which calls for a new housing operation mechanism.

Construction Solidarity is a cooperative housing mode proposed by Taiwanese architect Hsieh Ying-chun who has been devoted to light steel structure rural houses for about 17 years. Hsieh's team shows special concern about the relationship between the architects and residents: the architects simplify the construction procedure, provide an open system and deal with technical issues, while the residents reflect living conditions, cultural environment and religious beliefs. Under this mechanism, a semi-autonomous construction system responding to cultural diversity is formed and residents' community awareness is established during construction process, which may be a possible solution to Chinese rural housing problems mentioned above.

In 1999, Construction Solidarity was firstly adopted in the post-disaster reconstruction of the Thao community in Taiwan, and then was introduced into mainland China in 2004. So far it has been widely practiced in Hebei, Henan, Tibet, Sichuan and many other places in China. In reviewing the development

${ }^{*}$ PhD Student, Southeast University, China. 
history of Construction Solidarity, Hsieh's team has cooperated with different clients and participants, and confronted different natural environments, economic conditions, government policies and local customs, which have resulted in three major changes on development focuses, mainly including design, construction and operation. According to different housing concerns, the author divides the development progress of Construction Solidarity into the following three phases:

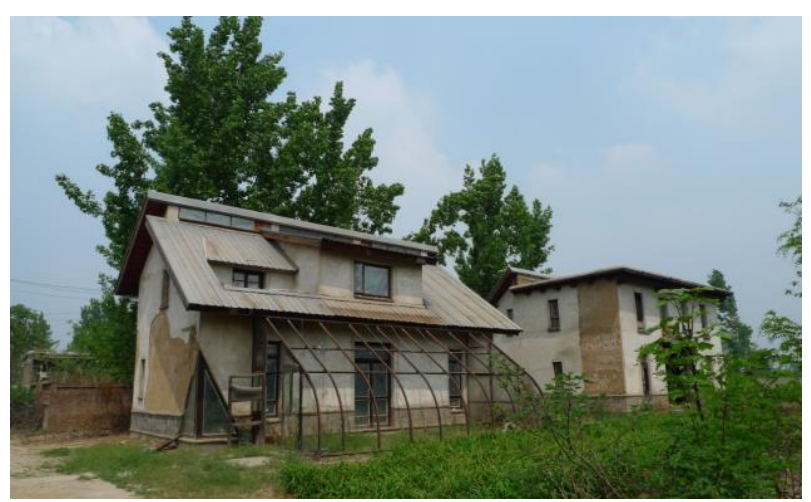

Figure 1. Earth House 001(on the right) and Earth House 002(on the left) Source: Author.

Firstly, demonstration of rural housing (2004-2006). Cooperating with Yen Yang-chu Rural Reconstruction Institute in Zhaicheng Village of Dingzhou, Hebei Province, Hsieh Ying-chun organized college student volunteers to construct a series of projects such as Earth House 001 and Earth House 002 (Figure 1), in order to research ecological housing. ${ }^{1}$

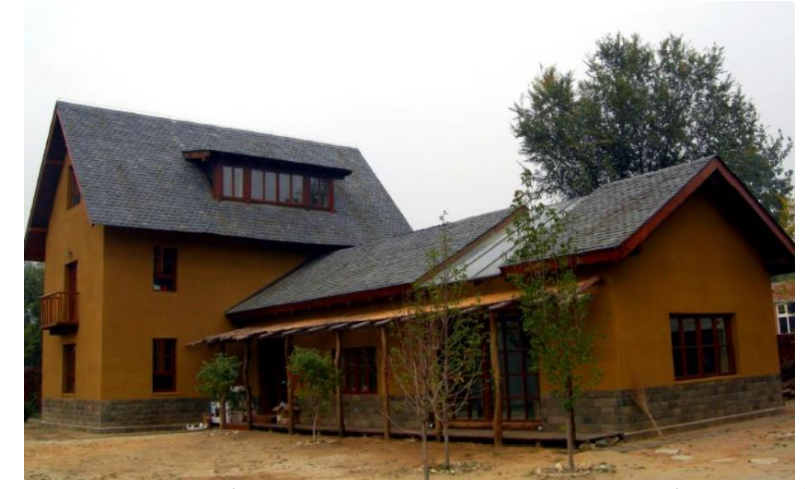

Figure 2. Cheng's House in Dongxincheng Village

Source: http://bit.ly/2cp59iY.

Secondly, promotion of ecological housing (2006-2008). Hsieh Yingchun's team mainly served for individual clients during this period, and took Construction Solidarity into practice in Hebei, Beijing, Anhui, Xizang and many other places. The representative works include House Renovation in

1. Bei-fang Li, "Hsieh Ying-chun's Luxury Thatched Cottage[J]," Nanfengchuang, February B (2006): 80-82. 
Lankao, Henan Province and Cheng's House (Figure 2) in Dongxincheng Village of Beijing.

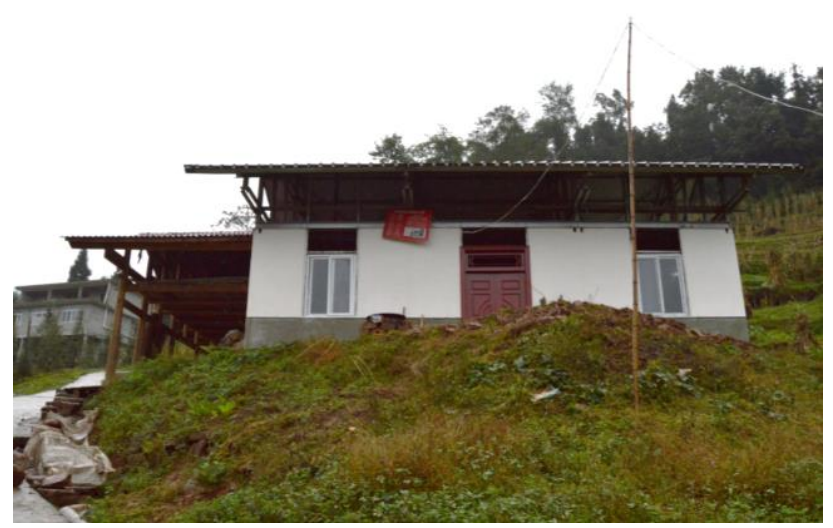

Figure 3. Wu's House in Qilao Village

Source: Author.

Thirdly, the combination between post-disaster reconstruction and ecological housing (2008-). After the outbreak of the Wenchuan earthquake in 2008, Hsieh Ying-chun's team built more than 500 light steel structure residences in the Sichuan Province, and has treated the southwest part of China as the main research and practice area since then. In 2013, his team participated in the post-earthquake rebuilding in Yaan (Figure 3), Sichuan Province.

Based on the three phases above, this paper chooses Zhaicheng Village of Hebei, Dongxincheng Village of Beijing, Qilao and Baishu Village of Sichuan as three typical research areas for each stage, makes comparisons between selfbuilt housing and Construction Solidarity cases, so as to find out different strategies of rural housing with architects' intervention.

\section{Conversion of Space Prototype with Zhaicheng Village for Example}

Zhaicheng Village, located about $15 \mathrm{~km}$ away from Dingzhou City, Hebei Province, is the birthplace of the first Chinese rural cooperative. It was known as the first village of modern villagers' democratic autonomy in China in the early twentieth century, and was selected by Hsieh as the starting point of promoting Construction Solidary in Mainland China.

The terrain here is plat, providing local people with considerable farmland to cultivate. Agriculture is the main economic source of the residents, which may be interfered by drought weather. Even though the traffic between this village and Dingzhou City is convenient today, the economy and life is still relatively independent, and the self-built houses represent the main characteristics of rural residential area in the North China Plain. 
The Prototype and Specialty of Rural Self-Built House

Most of the existing fork houses in Zhaicheng Village were built in 1980s, covering areas from about $0.3 \mathrm{mu}\left(200 \mathrm{~m}^{2}\right)$ to $0.6 \mathrm{mu}\left(400 \mathrm{~m}^{2}\right)$. The self-built houses adopt one-floor flat roof prototype (Figure 4) with life unit on the north side, closed courtyard on the south side and storage on the east side (accounting for more than $23 \%$ of the construction area). Although the households of self-built house Case B are better off, the plans of the two cases are almost the same, so are the dimensions of each room.
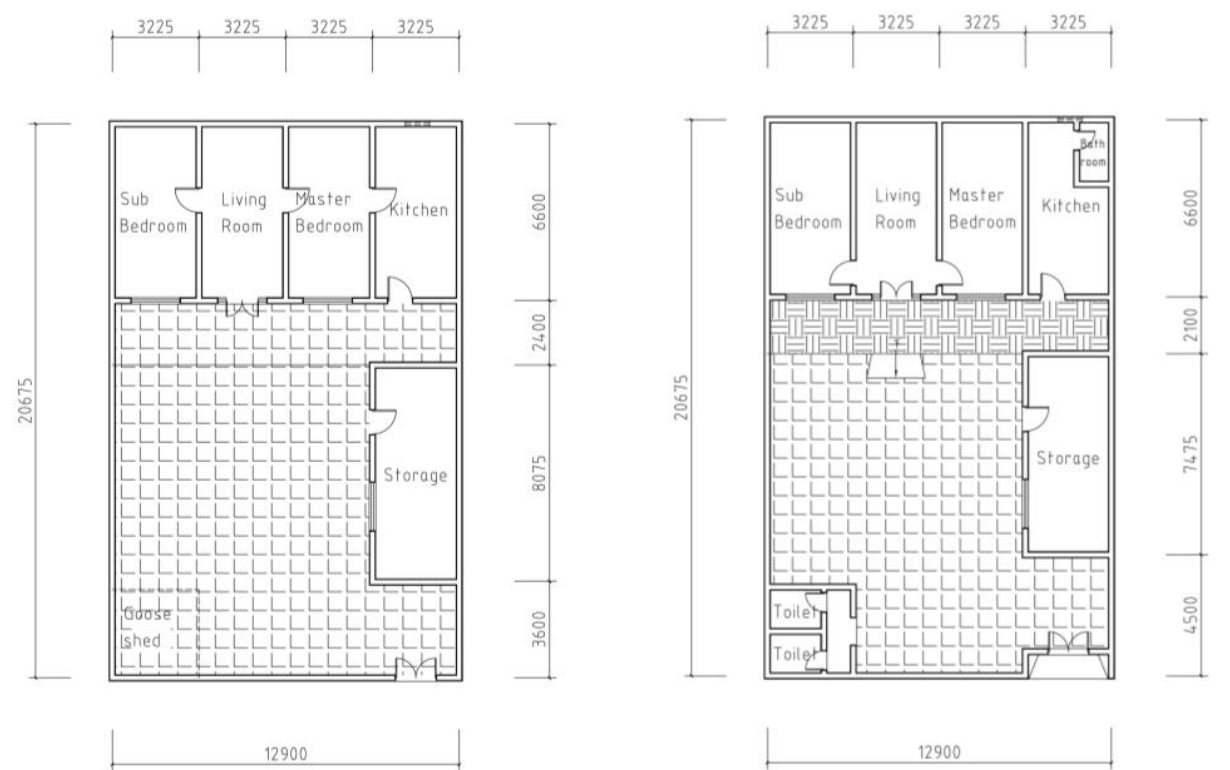

Figure 4. Plan of Self-built House Case A (on the left) and B (on the right) in Zhaicheng Village

Source: Drawn by the author.
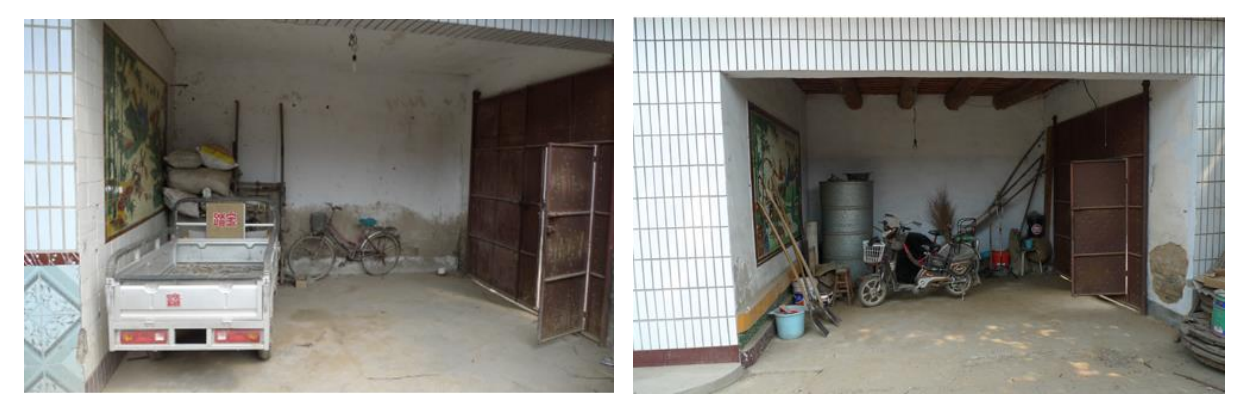

Figure 5. Entrance Space of self-built House Case A (on the left) and B (on the right) in Zhaicheng Village

Source: Author. 

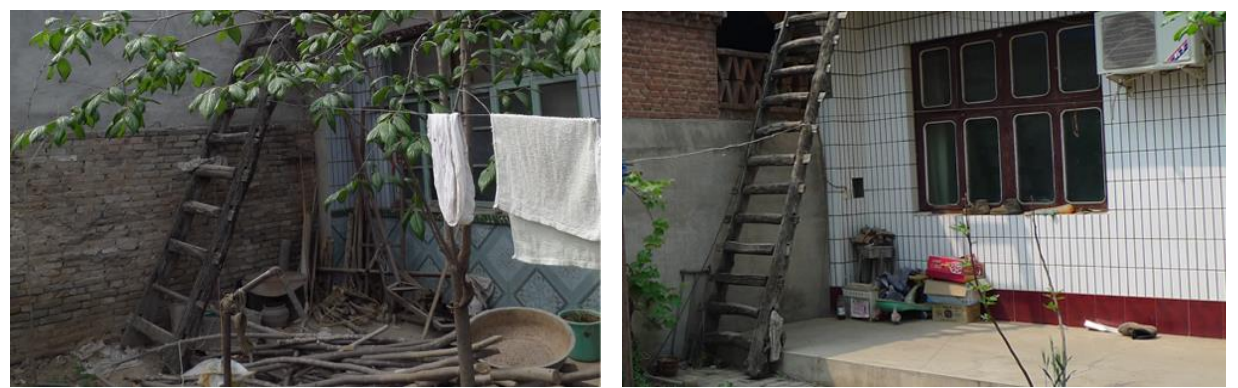

Figure 6. Ladder in the Courtyard of Self-built House Case A (on the left) and $B$ (on the right) in Zhaicheng Village

Source: Author.

The villagers' use of indoor and outdoor space is similar, which reflects the combination between agricultural production and daily life: The entrance space between the gate and screen wall stacks farm implements (Figure 5); The courtyard is used for breeding poultry, piling debris and parking farm machinery (Figure 6); The flat roof is used for drying grain, which can be reached by a ladder in the northwest of the courtyard; The heatable adobe sleeping platform (Figure 7), a traditional bed widely used in North China, is not only an energy saving furniture for sleeping but also a place for communication and rest, performing as the core of gathering family members and containing emotions and living memories of natives.

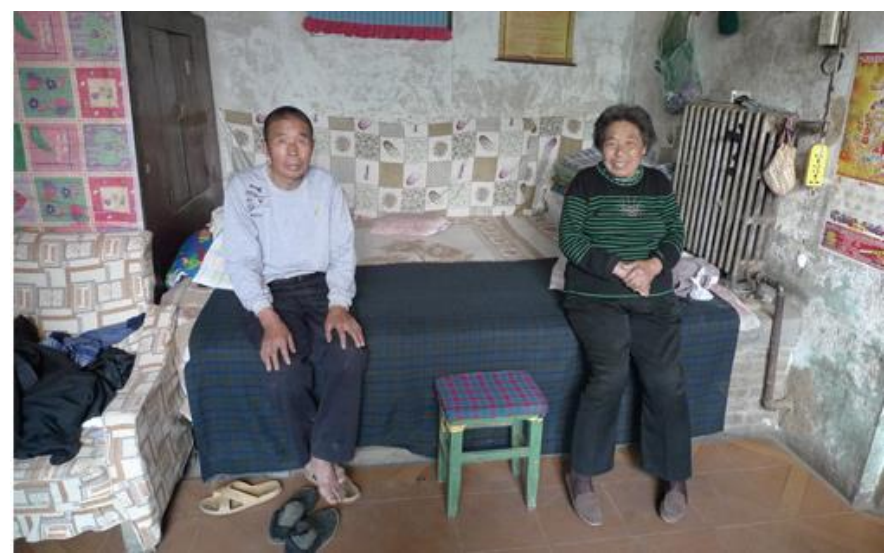

Figure 7. Heatable Adobe Sleeping Platform in Zhaicheng Village Source: Author.

Based on the prototype, the space operation is modular as well. "Jian" (Room in English) is natives' main measurement of housing size, which helps for the space and property division during the construction and living (Figure 8): firstly, the number of "Jian" is usually decided by family population; secondly, the craftsmen would leave the door openings of the walls behind when the construction is finished, in order to let the dwellers decide the relationship between two rooms; thirdly, the room function can be exchanged. 


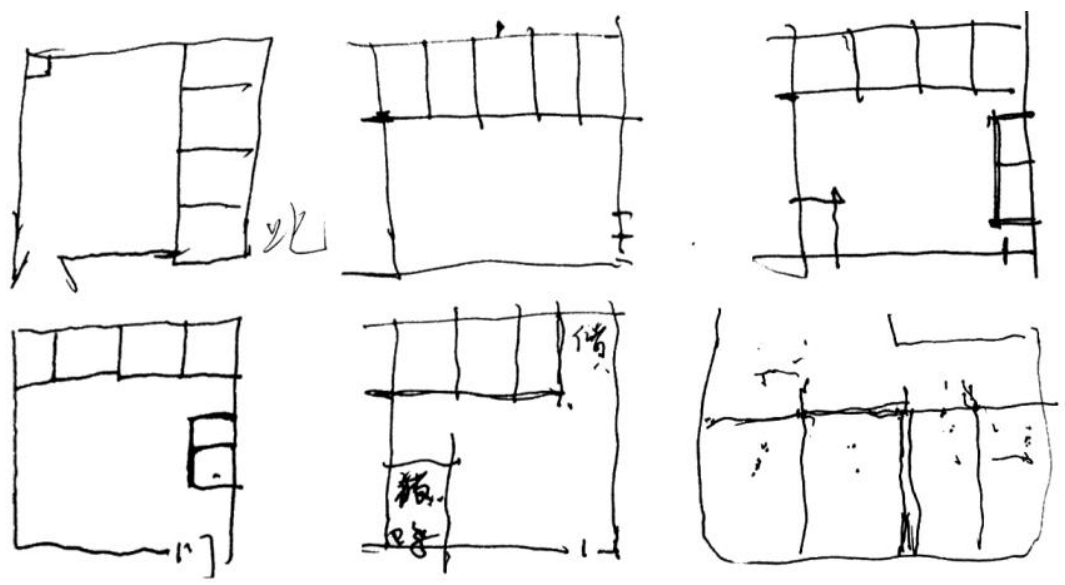

Figure 8. House Plans drawn by Interviewed Residents in Zhaicheng Village Source: Drawn by Natives in Zhaicheng Village and Collected by the Author.

With the same prototype, the housing diversity in Zhaicheng Village is expressed by introducing different room functions, which benefit from similar room size. The contradiction between traditional space and modern function is replied by adding south house in the courtyard, adding second floor of the north house and splitting the original room.

\section{Space Operation of Construction Solidarity}

Earth House 001 and Earth House 002, located in the campus of Yen Yang-chu Rural Reconstruction Institute, were built as demonstration houses to propagandize Construction Solidary. The two ecological houses adopt the same prototype within two floors and three rooms each (Figure 9), which reflects the local self-built residences. The inner space of the Earth House 001 extends half depth to add a kitchen, bathroom, staircase and places for lighting and ventilation, which do not exist in the local houses. Earth House 002 holds the plan form of three rooms each, and links two floors by single-flight stairs in the north of the house.
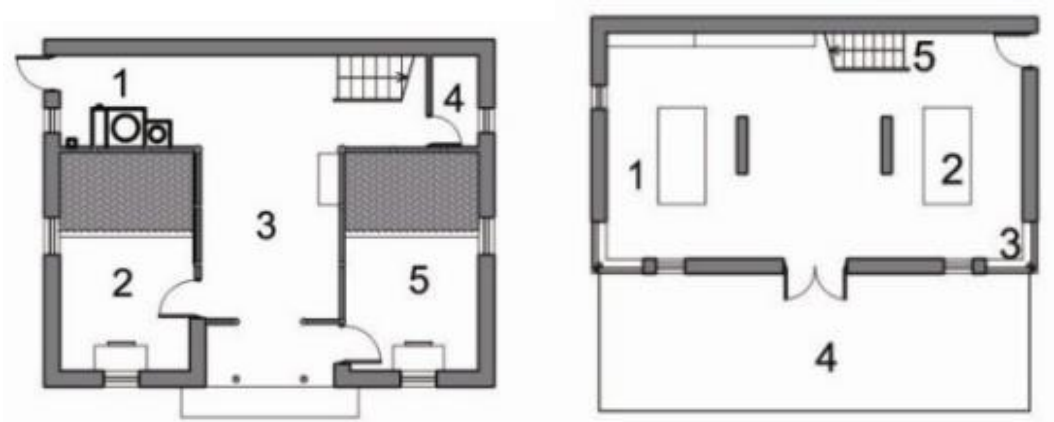

Figure 9. The First floor Plan of Earth House 001(on the left) and the Plan of Earth House 002 (on the right)

Source: http://bit.ly/2ckXQbm; http://bit.ly/2cjmdFp. 
The concept of Jian forms the order of space, which makes it possible to connect modular production and rural housing. Based on the thin-walled light steel structure and considering regional characteristics, length limit of raw materials, user acceptance, land area, construction cost and other factors, Hsieh Ying-chun's team selects modular dimensions of $1.1 \mathrm{~m}, 1.2 \mathrm{~m}, 1.22 \mathrm{~m}$ and so on. The modular system indicates the elasticity of Construction Solidarity: the clients can divide the interior space and change the functions of the room according to their needs, and the flexible adjunctions added by the users reflect the architectural diversity of rural housing.

Based on modulus, with the methods of increasing the number of floors and depth, changing northward fenestration to four sides, and transforming heatable adobe sleeping platform into double layer energy saving bedding, Construction Solidarity achieves the conversion of space prototype from the self-built rural housing (Figure 10), which increases space utilization efficiency, introduces new functions and brings about the original experience of rural life. However, the architect's concern on the custom of space utilization was still insufficient in Zhaicheng Village. For example, the slope roof makes it difficult to dry grain crops which the natives used to do, and the kindergarten is not as complete and inward as the folk houses

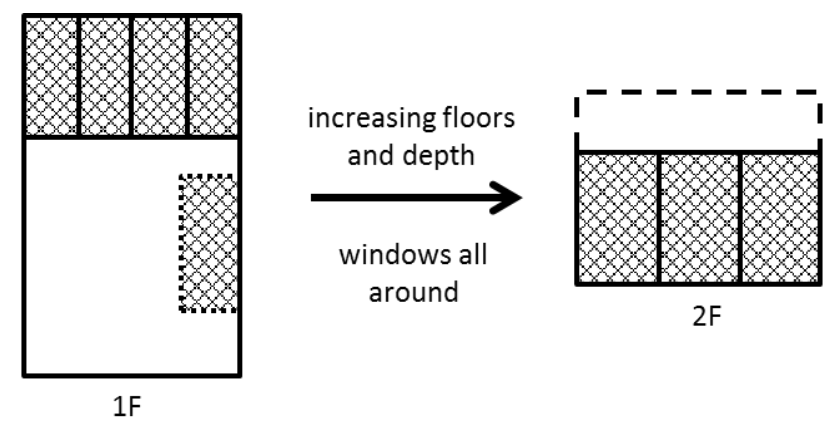

Figure 10. The Conversion of Space Prototype from the Self-built House (on the left) to Earth House 001 (on the right)

Source: Drawn by the author.

Besides the transformation of rural housing, the conversion of space prototype also includes the evolution of Construction Solidarity itself, which aims to maintain the sense of home. Based on the prototype which has already been accumulated, Hsieh Ying-chun's team takes social, cultural and aesthetic meaning into consideration by site analysis, and then adapts space, structure and detail to reach the design drawing, the construction drawing and the bill of material, which can continue optimizing the original prototype (Figure 11). 


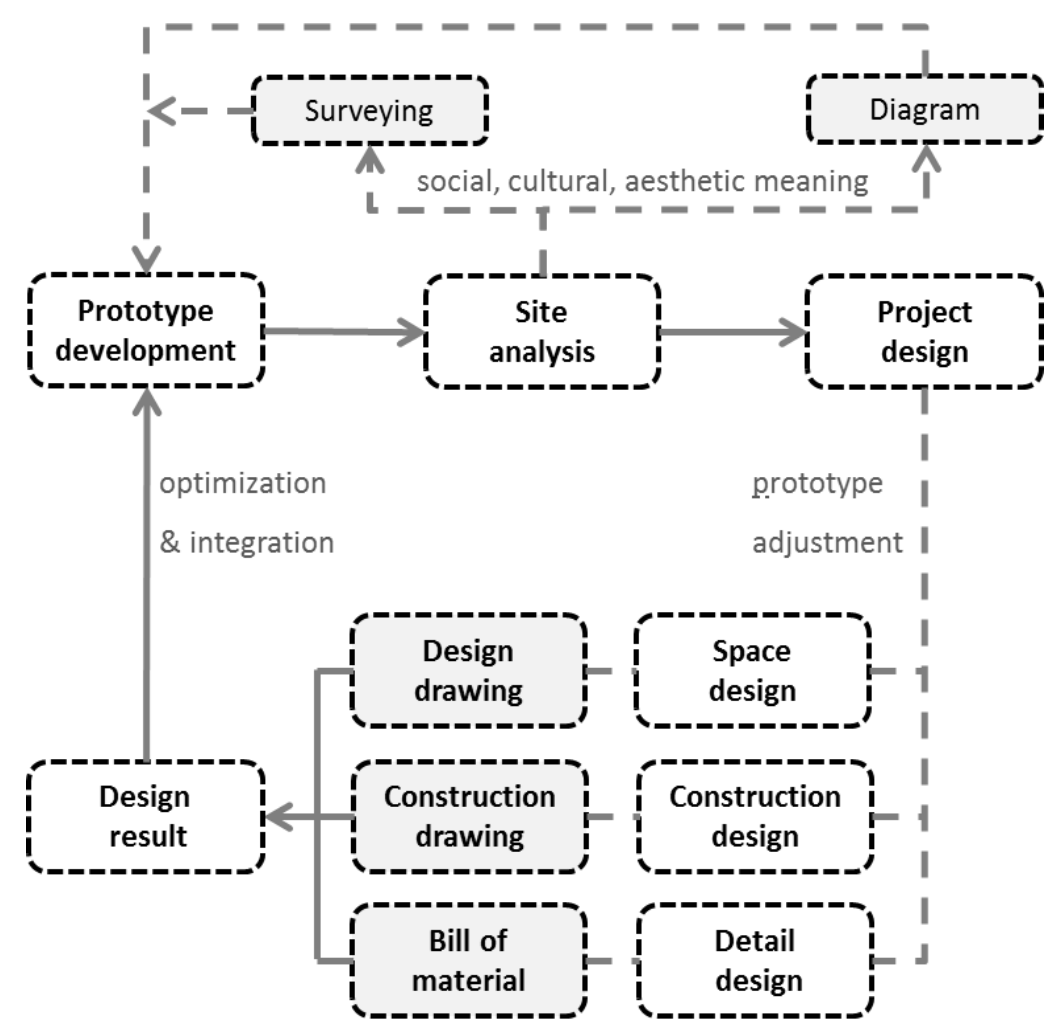

Figure 11. The Design Procedure of Construction Solidarity based on Prototype

Source: Drawn by the author.

\section{Simplification of Construction Technology with Dongxincheng Village for Example}

From 2006 to 2008, Hsieh's team had experimented on different building materials and structures. As a typical case of suburb village of metropolitans, the composition of residents in Dongxincheng Village is more complex, including scholars, wealthy who work in the center of Beijing and natives who engaged in light industry and service industry nearby, whose income levels and living habits are quite different. Under this circumstance, Hsieh's team adopted different structure systems, which reflects the improvement of the construction system and node details of Construction Solidarity.

\section{Rural Construction System Dominated by Brick Concrete Structure}

A majority of the houses in Dongxincheng Village are built in 2000s, which have large differences in area, but adopt similar "L" plan one-floor slope roof prototype with life unit on the north and courtyard on the south.

Similar to Zhaicheng Village, most self-built houses in Dongxincheng Village adopt brick concrete structure except very few luxury villas. Brick can divide space and be used as a load-bearing component, which can reach diversity by forming various kinds of wall. 
With the same structure system, the character of different houses is reflected by residents' selection - both positive choices of pavements, doors, windows, roof tiles and ridge beasts according to villagers' tastes and negative choices of elevation style (such as cornice, Figure 12) influenced by the trend of the times.
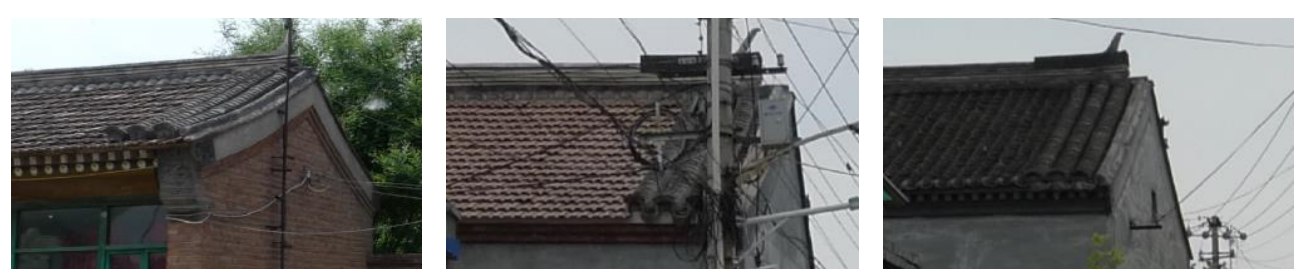

Figure 12. Different Cornice Masonry Ways in Dongxincheng Village Source: Author.
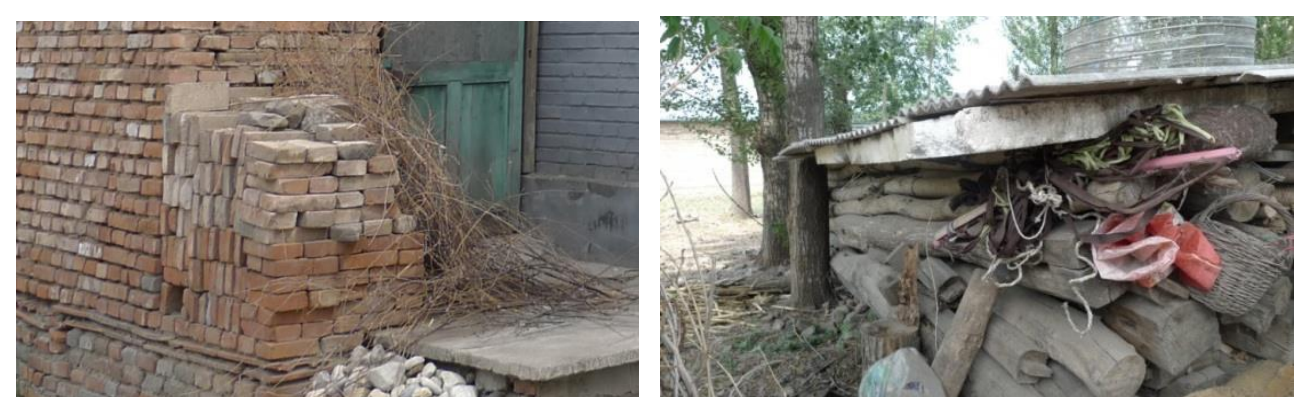

Figure 13. Building Material Storage Space in Dongxincheng Village Source: Author.

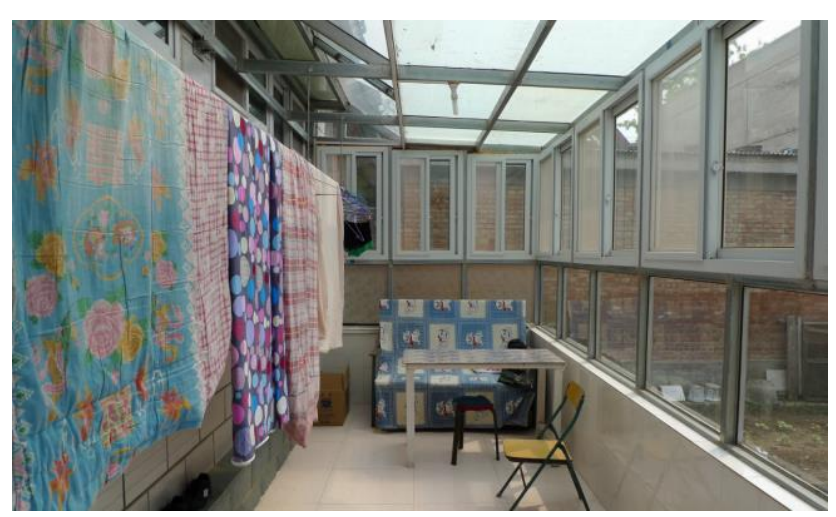

Figure 14. Self-renovation by Light Steel in Dongxincheng Village Source: Author.

The quality of the house is mainly evaluated by the residents' choice of cladding. Villagers who are relatively rich tend to create clean living environments with exterior wall tiles, cement floor leveling and an interior ceiling, while the low-income people maintain production and lives with bare brick walls, rammed earth floor, and indoor wooden beams. It means that the cladding is not only structure's shelter by material, but also practical function's are covered by art form. The villagers' attitude towards the covering layer 
makes the architecture express its beauty by means of structural symbols rather than structural technology.

After moving into new houses, the locals' concern with construction and material continues with the methods of reserving building materials in case of improvement (Figure 13) and self-renovation by themselves (Figure 14).

\section{Structure and Material Choice by Construction Solidarity}

Cheng's House is designed for a private client who works in a university in Beijing. This project, built by professional construction team in 2008, covers an area of about $2000 \mathrm{~m}^{2}$, including a three-story house and a courtyard surrounding it. The house is rather different from other rural housings in both internal function and external morphology, although it adopts a similar L shape plan. It is built by a wooden structure, which consists of a great deal of recycled timber. The cladding material is straw-clay, and double-layer glass is put to use in the windows. Despite the advantages of cost saving, energy conservation and environment protection, the tailor-made design and construction mode of Cheng's House is not suitable for popularization in rural housing at present.

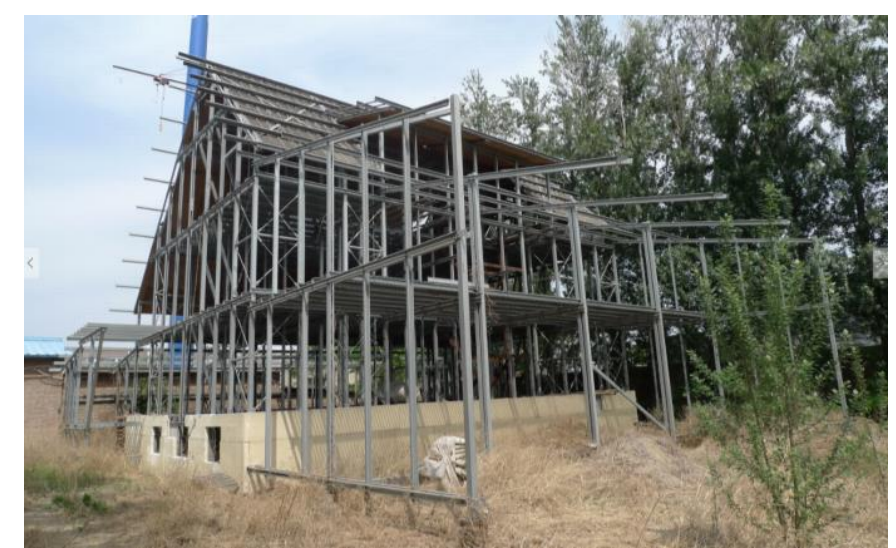

Figure 15. Status of Hsieh Ying-chun's Studio in Beijing, 2014

Source: Author.

Hsieh Ying-chun's Studio in Beijing (2012, Figure 15), located near Cheng's House, should have been built to promote Construction Solidarity, but suspended due to dispute over property rights. However, it still exhibits an advanced Light Steel Structure System whose body frame is made out of strengthened cold-formed steel (Figure 16). The frame consists of a main steel structure (Simplified to 2 kinds of sections to facilitate the industrial manufacturing), connection pieces (including bolts, rod and self-tapping screws to get rid of the welding procedure and to increase the strength of structure, which break through the bottleneck that existing architecture theories are facing) ${ }^{2}$ and a sporadic work piece (offcuts which reduce construction

2. Mo Li and Kong, “"Button's Button”: Hsieh Ying-chun's Open System Theory And Its Adaptability[J]," New Architecture, January (2014): 10-14. 
accuracy, but do not support the structure). The exterior wall is made of foam block and the roof is made of three-ply. The steel mesh lays on the floorslab.

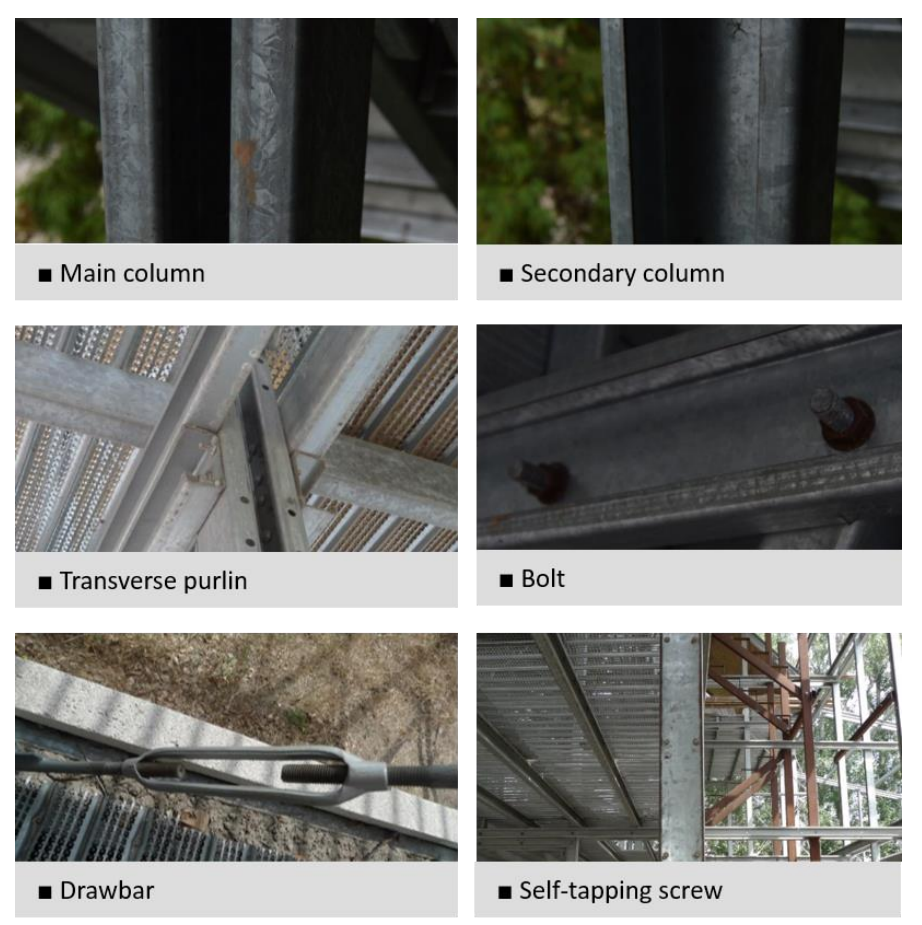

Figure 16. Components of Light Steel Structure System Source: Author.

Gradually, Hsieh Ying-chun's team combined industrial production and low-technology. On the one hand, special typed light steels and bolts whose structural strength is examined by the universal test machine are manufactured in the factory, which achieves the industrialization of housing. On the other hand, the construction operation is similar to the traditional through-jointed frame method, which is understandable for the villagers in southern mountain area. $^{3}$

The simplification of construction technology can be viewed as the prerequisite of Construction Solidarity, which is reflected on its progress from Cheng's House to Hsieh Ying-chun's Studio, from focusing on the construction of the whole building to the production of the light steel components, from emphasizing eco-friendly material such as straw-clay to paying attention to the material that the natives familiar with. For example, most villagers prefer to choose brick as the material of wall, which can both divide space and bear load. ${ }^{4}$

3. Chen Nie, Chen "Complex Adaptive System And Intersubjectivity: Experience of Reconstruction From Hsieh's House System[J]," Time+Architecture, January (2006): 78-81.

4. Andrea Deplazes, Constructing Architecture: Materials, Processes, Structures [M], Ren Zheng-yue (Dalian: Dalian University of Technology Press, 2007), 16-19. 


\section{Differentiation of Professional Orientation with Qilao and Baishu Village for Example}

After 2008, while carrying out post-disaster reconstruction projects by cooperating with the government and charity organizations, Hsieh's focus gradually shifted to the way to guide the villagers quickly, safely building houses and to reduce the cost. His practice in Yaan, Sichuan Province shows the improvement of operation.

Qilao and Baishu are two neighboring villages located in the mountainous area of Southwest China, where the weather is wet, rainy and lack of sunshine all year round. Although the arable land is very limited, most of the villagers earn their livings by farming, which restricts their incomes. The traffic is inconvenient, both in the village and the city.

General Operation of Rural Self-built Housing

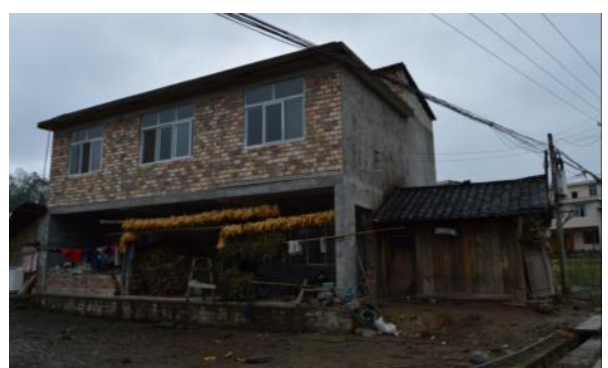

Figure 17. House Built by One Man in Qilao Village

Source: Author.

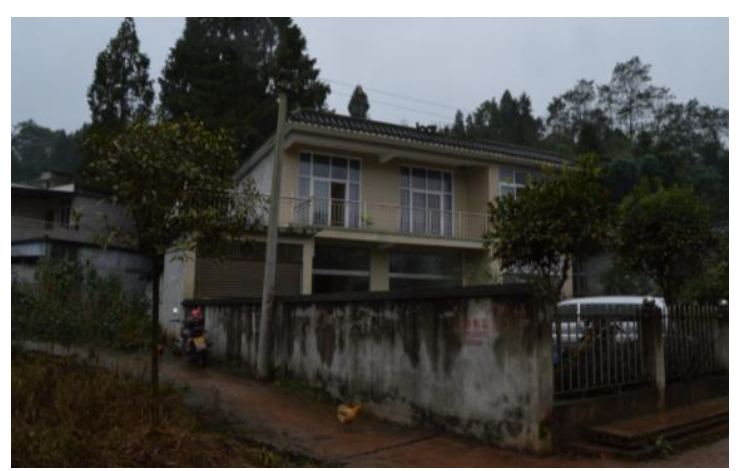

Figure 18. House Built by Construction Team in Baishu Village Source: Author. 
Table 1. Structural Material, Main Participants and Cost of Rural House Cases in Qilao and Baishu Village

\begin{tabular}{|c|c|c|c|c|}
\hline $\begin{array}{c}\text { Completed } \\
\text { Year }\end{array}$ & $\begin{array}{c}\text { Building } \\
\text { Area }\end{array}$ & $\begin{array}{c}\text { Structural } \\
\text { Material }\end{array}$ & Main Participants & Cost ( $¥$ ) \\
\hline $1950 \mathrm{~s}$ & $100 \mathrm{~m}^{2}$ & Wood & Villagers & Hardly Any \\
\hline $1970 \mathrm{~s}$ & $50 \mathrm{~m}^{2}$ & Wood & Villagers & Hardly Any \\
\hline 2000 & $200 \mathrm{~m}^{2}$ & Brick & Construction Team & 70,000 \\
\hline 2000 & $150 \mathrm{~m}^{2}$ & Brick & Villagers & 35,000 \\
\hline 2006 & $200 \mathrm{~m}^{2}$ & Brick & Construction Team & 55,000 \\
\hline 2008 & $200 \mathrm{~m}$ & Brick & Construction Team & 100,000 \\
\hline 2008 & $200 \mathrm{~m}^{2}$ & Brick & Construction Team & $\begin{array}{c}70,000 \\
\sim 80,000\end{array}$ \\
\hline 2011 & $200 \mathrm{~m}^{2}$ & Brick & Villagers & 20,000 \\
\hline 2012 & $400 \mathrm{~m}^{2}$ & Brick & Construction Team & 400,000 \\
\hline 2013 & $320 \mathrm{~m}^{2}$ & Brick & $\begin{array}{c}\text { Construction Team led } \\
\text { by Government }\end{array}$ & $\begin{array}{c}500,000 \\
\sim 600,000\end{array}$ \\
\hline 2013 & $200 \mathrm{~m}^{2}$ & Light Steel & $\begin{array}{c}\text { Rural Studio led by } \\
\text { Hsieh Ying-chun }\end{array}$ & 180,000 \\
\hline
\end{tabular}

Most self-built houses in Qilao and Baishu Village were built after 2000, mainly employing two story (partly three story) flat roof brick concrete prototype with similar operation.

The main participants of self-built housing are masons, carpenters, tenants, natives' relatives and friends. Usually the labor amount for a brick concrete house is 6-7, while sometimes a dwelling can be finished by only one adult (Figure 17). With the economic consciousness of the villagers and the improvement of their living standards, current operation form has been more diversified, and there are cases built by the construction team (Figure 18).

Land is the primary issue to be considered during construction. After the villagers get the land from the government, they can choose different ways to operate. There is hardly any design progress in self-built housing, because the house styles are imitated from the existing houses and the dimensions of room and joint are based on experience. During the construction period, it is necessary for builders and occupants to carry out building within larger allowable error, more adjustable space and more intuitive expectations, which means that open operation systems and low technology are very important.

The participants in traditional rural housing are not paid, but are always treated to a few meals instead. On this occasion, the progress to build a house is not only a behavior of production but also a kind of social activity, which helps to form consciousness of community on the basis of saving money (Table 1). 
Operation Mode and Price Control of Construction Solidarity

Inter-subjectivity is encouraged by Hsieh Ying-chun to deal with the relationship between the designers and occupants. ${ }^{5}$ After the architects set up an opening platform, the building workers and dwellers can participate in the construction progress, put forward design concepts from different perspectives and embody living conditions, cultural environment and religious beliefs through the residential.

The operation of the post-disaster reconstruction led by Hsieh Ying-chun in Qilao and Baishu Village mainly includes the following three stages:

First of all, preliminary preparation, Hsieh Ying-chun's team cooperates with the government, experts, scholars and contractors to solve the issues of raising funds, selecting construction land, calling for tenders of project and so on. Residents' advice is not directly involved in this phase.

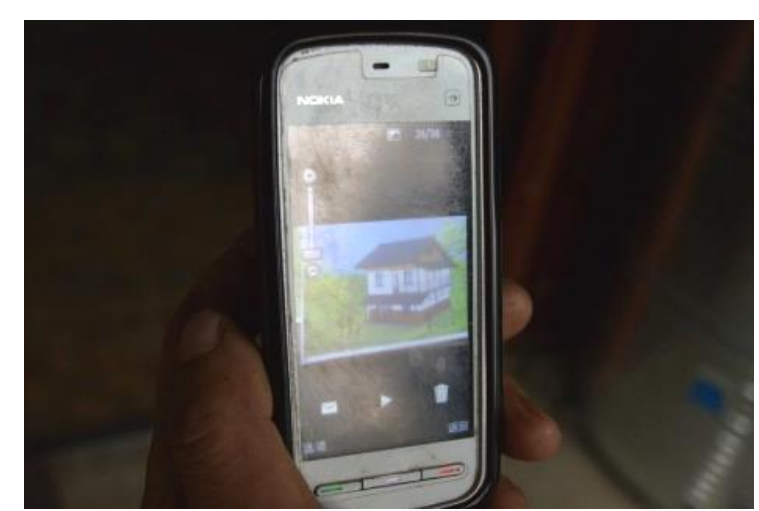

Figure 19. An Example of Design Sketch that Hsieh Ying-chun's Team Showed to the Villagers

Source: Author.

Secondly, design and production, the designer's team negotiates with the local government and the construction team of foundation during this period. After base research and project design, they help the government select housing types and build model houses. Because most of the villagers do not understand the blueprint, the designers explain their project to them by holding meetings and displaying design sketches (Figure 19).

Thirdly, collaborative construction, Hsieh Ying-chun's team partakes in assembling the labor force, instructing construction and safety supervision. The progress that the staff guides collaborative construction can be regarded as a continuous show. The architects strictly control the construction sequence and details, and help the locals build confidence. The villagers get command of the whole process by observing and imitating.

5. Xing Zhao, "Inter-subjective Open Architecture [J]," Urban Environment Design, July (2012): 202-204. 
There is a great difference in the charge mode between Construction Solidarity and usual design fee, ${ }^{6}$ because the cost of design is included in the production of light steel structure. The cost of the light steel structure is 700800 yuan $/ \mathrm{m}^{2}$ if the locals build houses all by themselves.

The process that unites modern architecture design, construction and operation with self-built housing demands both quasi-specialization of rural participants and differentiation of architects, which is different from conventional post-disaster reconstructions. ${ }^{7}$ The architects are not only designers but also producers and distributors by optimizing light steel structure and building open system. At the meantime, the architects do not control the occupants' own needs, but allow them to reach their full potential and awaken their collective consciousness. ${ }^{8}$

\section{Conclusions}

As a cooperative housing mode, Construction Solidarity has feasibilities in China from the following aspects: firstly, the operation of traditional self-built house construction in rural areas involves participation and mutual assistance of natives who are not only dwellers but also builders, which can be viewed as prototype of cooperative housing mode; secondly, most villagers have experiences of physical work such as farm work, woodwork and construction, which can be regarded as a practical basis to carry out house building; thirdly, the local people have strong desires to take part in design and construction of their own dwellings under the guidance of architects, which can not only meet the villager's needs of agricultural production and daily life but also improve the quality of construction.

Compared with self-built housing, both advantages and shortcomings of Construction Solidarity are expressed from the three aspects of design, construction and operation: in design, Construction Solidarity inherits the concept of the prototype from self-built housing, enables more flexibility in space division and introduces modern functions into rural houses, but the architects' understanding of rural life and accumulation of prototypes are not enough; in construction, Hsieh's team mainly adopts a light steel structure, which is energy-saving, light-weight, anti-seismic and allows a variety of options of wall, roof and other maintenance materials, but has technical difficulties in interior decoration, sound-proof and heat preservation; in operation, Construction Solidarity emphasizes architects' intervention and residents' participation, which guarantees house quality and speeds up construction, but requires more labors and does not have price advantage.

6. Xiao-dong $\mathrm{Xu}$, "From Reconstruction To The Ordinary People's Homes: Interview With The Architect Hsieh Ying-chun [J]," Designers \& Designing, June (2012): 16-23

7. Sun-quan Huang, "Three Contexts, Three Methods: The Sociality of Hsieh Ying-chun's Architecture [J]," New Architecture, January (2014): 4-9.

8. Ya-ning Wang, "Hsieh Ying-chun And His Construction Solidarity [J]," China Homes, January (2008): 98-101. 
After more than ten years of practice and research, Construction Solidarity has been highly-developed and represented three strategies in rural housing: firstly, the conversion of the space prototype has established the connection between the old and new, and has completed the space reconstruction on the basis of ensuring the villagers' sense of belonging; secondly, the simplification of construction has built the association between industrial manufacturing and low-tech construction, and has brought more choices for the locals by concentrating on Light Steel Structure System; thirdly, the differentiation of professional direction has set up the connection between the architects and the natives, and has combined modern architecture with traditional construction.

Construction Solidarity has proved the feasibility and necessity of architects' participation in rural housing. Nevertheless, there are still a lot of subjects for the designers and researchers to discuss: first of all, it is difficult to balance between inheritance and transcendence during the conversion the space; moreover, it is important to ensure high-quality design and construction standards during the simplification of technology; finally, it is essential to master the methods of communication and cooperation during the differentiation of profession.

Bibliography

Deplazes, Andrea. Constructing Architecture: Materials, Processes, Structures [M], Ren Zheng-yue. Dalian: Dalian University of Technology Press, 2007: 16-19.

Huang, Sun-quan. "Three Contexts, Three Methods: The Sociality of Hsieh Yingchun's Architecture [J]." New Architecture, January (2014): 4-9.

$\mathrm{Li}$, Bei-fang. "Hsieh Ying-chun's Luxury Thatched Cottage [J]." Nanfengchuang, February B (2006): 80-82.

Li, Mo and Kong. “ "Button's Button”: Hsieh Ying-chun's Open System Theory And Its Adaptability [J].” New Architecture, January (2014): 10-14.

Nie, Chen. "Complex Adaptive System And Intersubjectivity: Experience of Reconstruction From Hsieh's House System [J]." Time+Architecture, January (2006): 78-81.

Wang, Ya-ning. "Hsieh Ying-chun And His Construction Solidarity [J]." China Homes, January (2008): 98-101.

$\mathrm{Xu}$, Xiao-dong. "From Reconstruction To the Ordinary People's Homes: Interview With The Architect Hsieh Ying-chun [J].” Designers \& Designing, June (2012): $16-23$.

Zhao, Xing. "Inter-subjective Open Architecture [J]." Urban Environment Design, July (2012): 202-204. 